\title{
Corrosion Inhibition of Mild Steel in Hydrochloric Acid by Tannins from Rhizophora Racemosa
}

\author{
Makanjuola Oki ${ }^{1,2}$, Ebitei Charles ${ }^{3}$, Collins Alaka ${ }^{4}$, Tambari Kayode Oki ${ }^{1}$ \\ ${ }^{1}$ Department of Technical Services, Greenfield-Oaks Limited, London, UK; ${ }^{2}$ Department of Petroleum Engineering, Covenant Uni- \\ versity, Ota, Nigeria; ${ }^{3}$ Department of Mechanical Engineering, Niger Delta University, Yenagoa, Nigeria; ${ }^{4}$ Department of Pure \& \\ Industrial Chemistry, University of Port Harcourt, Port Harcourt, Nigeria. \\ Email:m.oki11@yahoo.com
}

Received December 11 ${ }^{\text {th }}$, 2010; revised February 15 ${ }^{\text {th }}$, 2011; accepted April $11^{\text {th }}, 2011$.

\begin{abstract}
Studies on the corrosion behaviour of mild steel electrodes in inhibited hydrochloric acid are described. Conventional weight loss measurements show that a maximum concentration of $140 \mathrm{ppm}$ of tannin from Rhizophora racemosa is required to achieve $72 \%$ corrosion inhibition. Similar concentration of tannin: $\mathrm{H}_{3} \mathrm{PO}_{4}$ in ratio $1: 1$ gave $61 \%$ inhibition efficiency, whereas efficiency obtained for phosphoric acid as inhibitor in the same environment was 55\%. Corrosion rates obtained over six hours of exposure in $1 \mathrm{M} \mathrm{HCl}$ solution at inhibitor concentrations of $140 \mathrm{ppm}$ are $2 \mathrm{~mA} / \mathrm{cm}^{2}$, $2.4 \mathrm{~mA} / \mathrm{cm}^{2}, 2.6 \mathrm{~mA} / \mathrm{cm}^{2}$ and $6 \mathrm{~mA} / \mathrm{cm}^{2}$ for tannin, tannin $/ \mathrm{H}_{3} \mathrm{PO}_{4}$ and $\mathrm{H}_{3} \mathrm{PO}_{4}$-inhibited and uninhibited specimens respectively. Natural atmospheric exposure studies revealed that specimens treated in $\mathrm{H}_{3} \mathrm{PO}_{4}$ resisted corrosion for three weeks, while tannin treated specimens suffered corrosion attack after one week of exposure tests.
\end{abstract}

Keywords: Inhibitor, Tannins, Corrosion Rate, Rhizophora Racemosa, Phosphoric Acid

\section{Introduction}

Rhizophora racemosa is in abundance in the Mangrove forests of southern Nigeria. The bark of its stem is rich in tannins which can be described as any group of naturally occurring phenolic compounds. Their basic structure consists of garlic acid residues which are linked to glucose via glycosidic bonds [1]. Thus tannins have an array of hydroxyl and carboxyl groups through which the molecules can adsorb on corroding metallic surfaces. Ferrous materials, especially mild steel, on the other hand are largely used in acidic media in most industries including oil/gas exploration and ancillary activities. During such activities, inhibited hydrochloric acid is widely used in pickling, descaling and stimulation of oil wells in order to increase oil and gas flow. The inhibitors employed are varied and some have been found to be hazardous to health and the environment at large [2]. Thus efforts are now directed towards formulation of modern environmentally safe inhibitors [3] in which plant extracts have become important as eco-friendly, economical, readily available and renewable sources of effective corrosion inhibitors. Other researchers [4-8] have demonstrated corrosion inhibition in the order of $80 \%$ and above by extracts from Mentha Pulegium [4], Azadirachta
[5], and Zenthoxylum alatum [6], Kidney bean [7] and Occimum viridis [8] amongst many others. The inhibition efficiency has been described as primarily due to their adsorption at corroding metal surfaces [9]. A protective film forms due to adsorption of these inhibitor molecules which restricts either the movement of ions away from the corroding surface or the consumption of electrons; however in most cases, they act as both anodic and cathodic inhibitors [10]. It is not uncommon to use either tripolyphosphates or phosphoric acid [11] and/or a mixture of either with other inhibitors to inhibit the corrosion of mild steel especially in the petrochemical industry. In such cases synergistic effects where improved corrosion inhibitive efficiency is observed, lower costs implications of using either of the two are the primary motives.

Thus, the present investigation is directed at the evaluation of tannin from Rhizophora racemosa, phosphoric acid and a combination of the two as inhibitors for the corrosion of mild steel in hydrochloric acid.

\section{Experimental}

\subsection{Materials}

Mild steel specimen which contained, Carbon, $0.16 \%$; 
Magnesium 0.53\%; Silicon 0.16\% and Iron 99.25\% was made out into electrodes. All chemicals used were of laboratory grade by BDH Chemicals, UK, while tannin was obtained from the bark of Rhizophora racemosa. Distilled water was used throughout the experiment.

\subsection{Methods}

Tannin was extracted from the bark of Rhizophora racemosa by the methods described by Ojinnaka [12]. Mild steel specimens of dimensions $40 \times 20 \times 4 \mathrm{~mm}$ were made into electrodes by fastening each on to Copper wire, $100 \mathrm{~mm}$ in length through a notch at one end and consolidated with Araldite, an epoxy resin. The final exposed area of each electrode was $20 \times 20 \times 4 \mathrm{~mm}$ respectively, giving an exposed total surface area of $10.4 \mathrm{~cm}^{2}$. Prior to exposure to various corrosive media, the specimens were abraded with emery paper after which the specimens were individually rinsed in ethanol, dried under the fan and stored in desiccators prior to use in the experiments. Weight loss measurements were carried out by immersing each pre-weighed electrode in $100 \mathrm{ml}$ of 1 $\mathrm{M}$ of $\mathrm{HCl}$ to act as control. Other electrodes were similarly exposed in $1 \mathrm{M} \mathrm{HCl}$ media containing various concentrations of tannin. During exposure, the potentials of the various specimens were measured with reference to saturated calomel electrode connected through a high impedance voltmeter. Triplicate experiments were performed in each case and the mean values of the weight loss recorded. The specimens were then examined under Olympus optical metallographic microscope. Further, electrodes immersed in concentrated inhibitor solutions for 10 minutes each and dried under the fan for 30 minutes and untreated specimens were exposed vertically to the outside environment behind the laboratory at Choba, Port Harcourt, Nigeria. These specimens were observed regularly and at the end of 21 days, the electrodes were examined under an Olympus metallographic microscope.

Similar tests as described above were performed on mild steel electrodes with phosphoric acid and tannin: phosphoric acid in ratio 1:1 as inhibitors of interests.

\section{Results and Discussions}

\subsection{Atmospheric Exposure}

General Observations

To the naked eye, untreated mild steel specimens showed some red-brown patches of rust on the first day of exposure to the atmosphere. This is expected as the corrosion product of iron exposed to moist air, ferrous hydroxide is further oxidised to the hydrated oxide during exposure. However, those specimens treated with tannin, tannin/phosphoric acid and phosphoric acid, retained the colourations imparted on them by the respective inhibitor solutions.

For those specimens treated with phosphoric acid and tannin/phosphoric acid, there was no rust exhibited over three weeks of exposure as the phosphate formed a tenacious film which is integral with the substrate and protected the surface from the inclement atmosphere. However the specimens treated with tannin solution showed some signs of rust after one week of exposure to the atmosphere. Researchers [5,6,13] agree that inhibitors of organic origin perform by adsorbing on substrates through weak bonds. The bonds formed by tannin with the mild steel substrates were compromised thus exposing the substrate to the atmosphere and corrosion reactions with formation of rust occurred.

These observations were further confirmed with optical microscopy examination of the various specimens.

\subsection{Corrosion Rates and Inhibition Efficiencies}

During this investigation corrosion rates, $C R$ and percent efficiency, $E \%$ were derived from Equations (1) and (2) respectively as demonstrated by other researchers $[6,8$, 13].

$$
C R=w_{o}-w / A t
$$

where $w_{o}$ and $w$ are, respectively, the weights of the specimens before and after exposure to $1 \mathrm{M}$ hydrochloric acid; $A$ is the total surface area, $10.4 \mathrm{~cm}^{2}$ in this investigation and $t$ is the time of exposure.

$$
E \%=\left(C R_{o}-C R_{i}\right) \times 100 / C R_{o}
$$

where, $C R_{o}$ and $C R_{i}$ are the corrosion rates of mild steel in $1 \mathrm{M} \mathrm{HCl}$ without and in the presence of various concentrations of different inhibitors respectively and $E \%$ are the inhibition efficiency.

The weight loss of mild steel in $1 \mathrm{M} \mathrm{HCl}$ solution initially increased rapidly with a rate that decreased with time, Figure 1, as a result of formation of corrosion products which may stifle corrosion reactions when deposited on the substrate [14].

After 6 hours of exposure, the weight loss was $413 \mathrm{mg}$, which translates to a corrosion rate, CR of $6.619 \mathrm{mg} / \mathrm{cm}^{2} / \mathrm{h}$. At that instance and beyond, the electrode potential, as measured with respect to saturated calomel electrode through a high impedance voltmeter, was $-1.490 \mathrm{~V}$.

For iron corroding freely as $\mathrm{Fe} \pm \mathrm{Fe}^{2+}+2 \mathrm{e}^{-}, 2.51$ mdd is equivalent to $1 \times 10^{-6} \mathrm{~A} / \mathrm{cm}^{2}$ [15]. Thus, $6.619 \mathrm{mg} / \mathrm{cm}^{2} / \mathrm{h}$ is equivalent to about $6 \mathrm{~mA} / \mathrm{cm}^{2}$.

Figure 2 describes the efficiency of tannin, tannin/ phosphoric acid and phosphoric acid respectively in $1 \mathrm{M}$ $\mathrm{HCl}$, where it is observed that tannin showed a maximum efficiency of about $72 \%$ at a concentration of $140 \mathrm{ppm}$ whereas, at the same concentration, efficiencies of about $61 \%$ and $55 \%$ were achieved by tannin $/ \mathrm{H}_{3} \mathrm{PO}_{4}$ and $\mathrm{H}_{3} \mathrm{PO}_{4}$ 


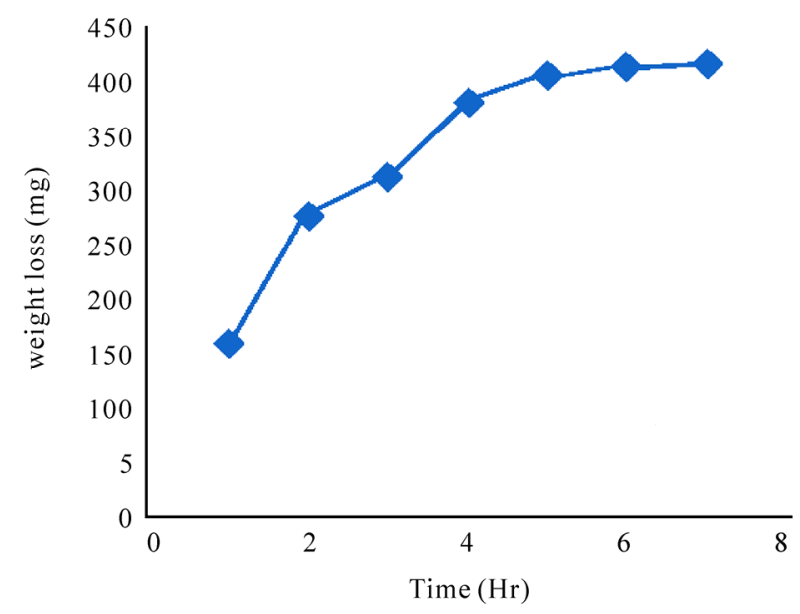

Figure 1. Weight loss of mild steel specimen with time in $1 \mathrm{M} \mathrm{HCl}$ at $30^{\circ} \mathrm{C}$.
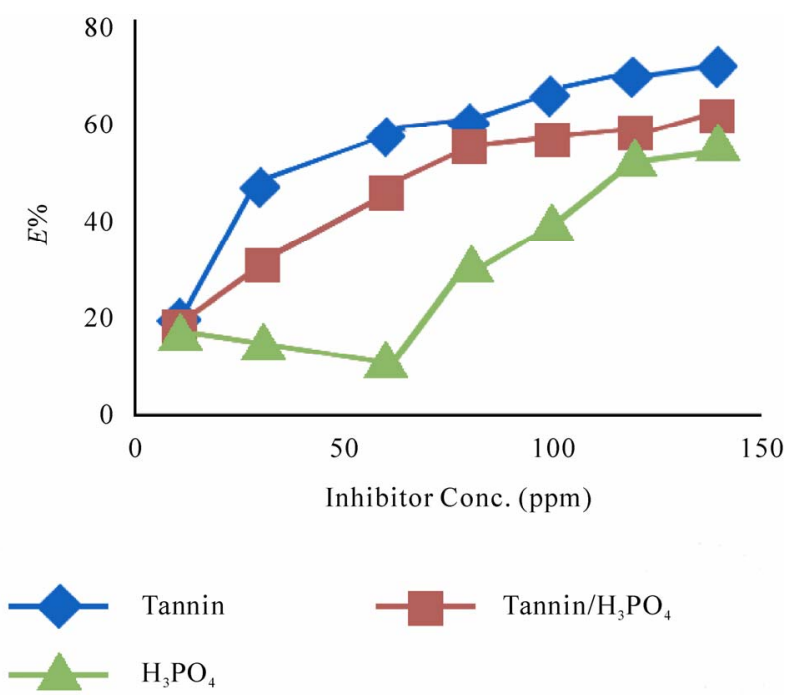

Figure 2. Efficiency of various inhibitors on the corrosion of mild steel in $1 \mathrm{M} \mathrm{HCl}$ at $30^{\circ} \mathrm{C}$.

respectively. For tannin and tannin/ $\mathrm{H}_{3} \mathrm{PO}_{4}$, efficiencies increased with increase in concentration which is in agreement with the findings of other researchers $[8,13]$ who employed organic based compounds as inhibitors for mild steel in various concentrations [6,7] and types $[10,11]$ of acids. However, of interest is the characteristic behaviour exhibited by the specimen in the presence of $\mathrm{H}_{3} \mathrm{PO}_{4}$ as inhibitor in $\mathrm{HCl}$ solution, Figure 3. The curve for the corrosion rate of mild steel in the presence of $\mathrm{H}_{3} \mathrm{PO}_{4}$, showed a maximum value on adding $60 \mathrm{ppm}$ of the inhibitor, which is also demonstrated as the lowest point on the efficiency curve in Figure 2 Phosphates are passivators which form mixed iron oxide/phosphate films on mild steel in aqueous corrosion systems. However for passivation to occur, the corrosion current density for the specimen must be driven beyond a critical
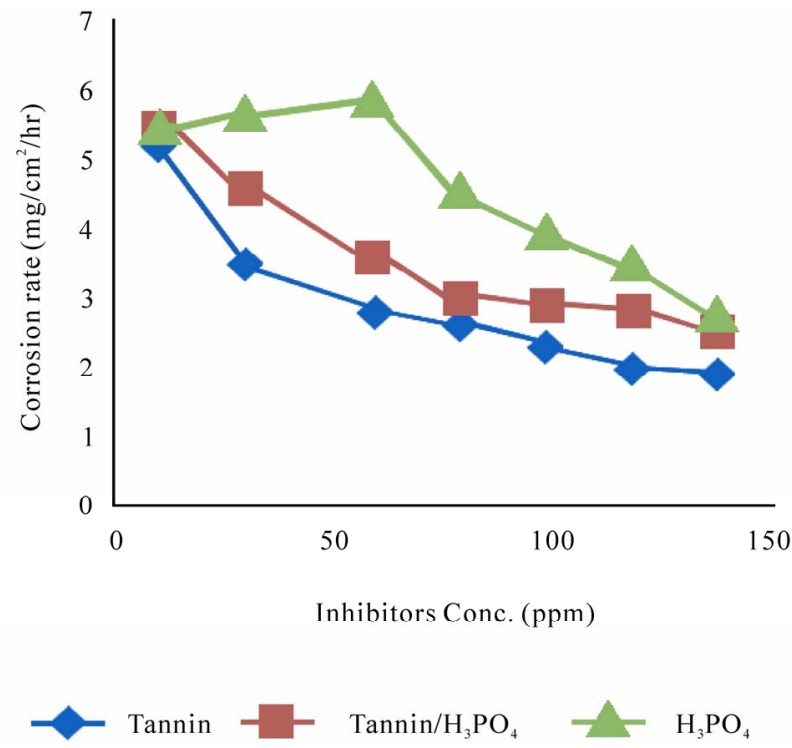

Figure 3. The corrosion rates of mild steel in $1 \mathrm{M} \mathrm{HCl}$ in the presence of various inhibitors at $30^{\circ} \mathrm{C}$.

point, $i_{\text {crit }}$, when the corrosion rate will drop sharply as its electrode potential for passivation, $E_{p p}$, is attained. The critical corrosion density was attained on adding 100 ppm of $\mathrm{H}_{3} \mathrm{PO}_{4}$ to the corroding system and the potential recorded at this point and beyond was about $-1.105 \mathrm{~V}$ with respect to saturated calomel electrode, SCE. This potential is more positive than $-1.490 \mathrm{~V}$, recorded for mild steel in $1 \mathrm{M} \mathrm{HCl}$ without inhibitor, indicating the formation of a film over the surface of the electrode. The free corrosion potential recorded for the specimen in the presence of tannin as inhibitor was about $-1.042 \mathrm{~V}$ wrt SCE, which is equally more positive than $-1.490 \mathrm{~V}$ as reported earlier in the absence of an inhibitor. In this respect, although a film had formed over the surface of the electrode, it may not be as compact as those formed in the presence of phosphates in a similar environment. However, the magnitudes of potential in all cases do not signify the extent of corrosion which is determined by kinetic factors; it gives an indication of the magnitude of the $\mathrm{pH}$ at the electrode's interphase with the electrolyte.

The corrosion rates as calculated from weight loss measurements for the various specimens at inhibitor concentration of $140 \mathrm{ppm}$ for six hours of exposure are equivalent to $2 \mathrm{~mA} / \mathrm{cm}^{2}, 2.4 \mathrm{~mA} / \mathrm{cm}^{2}, 2.6 \mathrm{~mA} / \mathrm{cm}^{2}$ for tannin, phosphoric acid and tannin/phosphoric acid respectively, using the relationship quoted earlier.

For organic inhibitors such as the tannins which inhibit corrosion by adsorption, the surface coverage, $\theta$, often gives insight into the mode(s) of interaction of their molecules with the corroding substrate. Some of the adsorption isotherms, $[16,17]$ which relate $\theta$ to $C$, the concentration of the inhibitor in the corroding system are Langmuir isotherm, $(C / \theta$ Vs $C)$, which assumes that 
there is no interaction between adsorbed molecules on the surface. Others are Temkin $(\theta$ Vs $\log C)$ and Frumkin $(\theta$ Vs $C)$; these assume the effect of multiple layer and some interactions between molecules on the surface respectively. For tannin and phosphoric acid as inhibitors, the data derived from the gravimetric studies obeyed the Langmuir adsorption isotherm. However for tannin/ $\mathrm{H}_{3} \mathrm{PO}_{4}$, as inhibitor, none of the isotherms clearly defined its mode of interactions on the substrates.

\section{Conclusions}

At a concentration of 140ppm, tannin has efficiency of $72 \%$, tannin: $\mathrm{H}_{3} \mathrm{PO}_{4} 61 \%$ and $\mathrm{H}_{3} \mathrm{PO}_{4}$ showed $55 \%$ efficiency in $1 \mathrm{M} \mathrm{HCl}$.

Mild steel specimens treated in $\mathrm{H}_{3} \mathrm{PO}_{4}$ were protected against atmospheric attack for three weeks while those treated in tannin resisted corrosion for one week.

\section{Acknowledgements}

C. O Alaka acknowledges the Head of Department, Department of Pure and Industrial Chemistry, University of Port Harcourt for the use of laboratory facilities.

\section{REFERENCES}

[1] G.-I. Nonaka, "The Isolation and Structure Elucidation of Tannins," Pure and Applied Chemistry, Vol. 6, No. 3, 1989, pp. 357-360. doi:10.1351/pac198961030357

[2] A. Veawab, P. Totinwachwuthikul and A. Chakma, "Investigation of Low-Toxic Corrosion Inhibitors for Carbon Dioxide Separation Process Using Aqueous MEA Solvent,” Industrial \& Engineering Chemistry Research, Vol. 40, No. 22, 2001, pp. 4771-4777. doi:10.1021/ie010248c

[3] B. Raja and M. G. Sethuraman, "Inhibitive Effect of Black Pepper Extract on the Sulphuric Acid Corrosion of Mild Steel,” Materials Letter, Vol. 62, No. 17-18, 2008, pp. 113-116. doi:10.1016/j.matlet.2007.04.079

[4] A. Bouyanzer, B. Hammouti and L. Majidi, "Pennyroyal Oil from Menthapulegium as Corrosion Inhibitor for Steel in $1 \mathrm{M} \mathrm{HCl}$," Material Letters, Vol. 60, No. 23, 2006, pp. 2840-2843. doi:10.1016/j.matlet.2006.01.103

[5] P. C. Okafor, E. E. Ebenso and U. J. Ekpe, “Äzadirachta Indica Extracts as Corrosion Inhibitor for Mild Steel in Acid Medium," International Journal Electrochemical Science, Vol. 5, No. 7, 2010, pp. 978-984.
[6] L. R. Chaulhan and G. Gunasekaran, “Corrosion Inhibition of Mild Steel by Plant Extract in Dilute HCl Medium," Corrosion Science, Vol. 49, No. 3, 2007, pp. 1143-1161. doi:10.1016/j.corsci.2006.08.012

[7] Y. Abed, B. Hammouti, F. Touhami, A. Aouniti, S. Kertit, A. Mansri and K. Elkacemi, "Poly (4-Vinylpyrindine) (P4VP) as Corrosion Inhibitors of Armco Iron in Molar Sulphuric Acid Solution,” Bulletin of Electrochemistry, Vol. 17, No. 3, 2001, pp. 105-108.

[8] E. E. Oguzie, "Studies on the Inhibitive Effects of Occimum Viridis Extracts on the Acid Corrosion Ofmild Steel," Materials Chemistry and Physics, Vol. 99, No. 2-3, 2006, pp. 441-445. doi:10.1016/j.electacta.2004.04.030

[9] G. Gunasekaran and L. R. Chaulhan, "Ecofiendly Inhibitors for the Inhibition of Mild Steel in Phosphoric Acid Medium,” Electrochimica Acta, Vol. 49, No. 25, 2004, pp. 4387-4395.

[10] M. Abdallah, E. E. Helal and A. S. Fouda, "AminoPyrimidine Derivatives as Inhibitors for Corrosion of 1018 Carbon Steel in Nitric Acid Solution,” Corrosion Science, Vol. 48, 2006, pp. 639-643. doi:10.1016/j.corsci.2005.06.020

[11] L. S. Moiseeva and Y. Y. Tur, "The Role of Combined Corrosion Inhibitor Contact Time in Neutral Aqueous Media," Chemical and Petroleum Engineering, Vol. 59, No. 5-6, 2003, pp. 298-302. doi:10.1023/A:1025627502442

[12] C. M. Ojinnaka, “Tanner’s Guide to Nigerian Plants,” Leather Research Institute of Nigeria, Zaria, 1988.

[13] E. Chaieb, A. Bouyanzer, B. Hammouti and M. Berrabh, "Limonene as Green Inhibitor for Steel Corrosion in $\mathrm{HCl}$ Solutions," Acta Physico-Chimica Sinica, Vol. 25, No 7, 2009, pp. 254-258.

[14] U. Rammelt, S. Kohler and G. Reinhard, "EIS Characterization of the Inhibition of Mild Steel Corrosion with Carboxylates in Neutral Aqueous Solution," Electrochimica Acta, Vol. 53, No. 23, 2008, pp. 6968-6972. doi:10.1016/j.electacta.2008.01.004

[15] E. Bardal, “Corrosion and Protection,” Springer Verlag London Ltd., London, 2004.

[16] I. Langmuir, “The Adsorption of Gases on Plane Surfaces of Glass, Mica and Platinum," Journal of American Chemical Society, Vol. 40, No. 9, 1918, pp. 1361-1403.

[17] A. N. Frumkin, "Electrocapillary Curve of Higher Aliphatic Acids and the State Equation of the Surface Layer,” Physical Chemistry, Vol. 116, 1925, pp. 466-470. 